\title{
UK magazine advertising portrayals of older adults: a longitudinal, content analytic, and a social semiotic lens
}

\author{
By VIRPI YLÄNNE*
}

\begin{abstract}
The focus of this article is the depiction of older adults in UK magazine advertising. Theoretically located in the broad area of cultural gerontology, with its central focus on culturally constitutive meaning of age(ing) (e.g. Twigg \& Martin 2015), it applies social semiotic categories (Kress \& van Leeuwen 1996, 2004) and draws on critical discourse analytic insights in investigating persistent trends in advertising images of older adults. These are linked with the role of advertising media in constructing and contributing to specific social "imaginary" or "imagination" of later life. A content analytic comparison between two corpora of adverts (221 ads from 1999 to 2004 and 313 ads from 2011 to 2016) reveals only minor changes over time. These include relative consistency in the product categories linked with older models, the adverts predominantly targeting older adults, but a decline in humorous portrayals. A semiotically oriented analysis of a subset of adverts further examines their compositional and affective dimensions, in addition to representational qualities. This uncovers strategies that are in line with aspirational third age discourse and imagery, but which also contribute to the marginalisation of older adults via a restricted portrayal of later life(styles) and can also be seen to problematise "ageless" depictions.

Keywords: advertising, agelessness, content analysis, older adult lifestyles, print media, social semiotic analysis.

Virpi Ylänne, Centre for Language and Communication Research, Cardiff University, Cardiff, Wales, UK
\end{abstract}


International Journal of Ageing and Later Life

\section{Introduction}

A cultural dimension in the analysis of ageing has increased in age studies (e.g. Gullette 2004, 2015; Katz 2005; Twigg \& Martin 2015), in line with postmodern orientations to age as an aspect of identity that is to an extent malleable via consumption and lifestyle choices. Furthermore, a cultural angle is advocated in the resistance to ageism. This study uses content analysis and a social semiotic approach to investigate persistent trends in advertising images of older adults in the UK and links these with the role of advertising media in constructing and contributing to specific social "imaginary" (e.g. Higgs \& Gilleard 2020) or "social imagination" (Blaikie \& Hepworth 1997) of later life. Work in critical discourse analysis has shown how media texts are written and read against the concurrent social, cultural, political and economic background, and discourse is seen as social practice (e.g. Fairclough \& Wodak 1997). This study similarly takes the view that media texts and images are not simply reflective of societal/ cultural ideologies but are instead "socially constitutive as well as socially shaped" (Fairclough \& Wodak 1997: 258). Furthermore, they function as resources for us to learn about age and ageing, even if we cannot expect them to determine readers' behaviour in a simple way. The relevant wider context surrounding the study is consumer culture, advertising and third age imagery.

Interest in media portrayals of older adults has been growing in recent years (for reviews, see, e.g., Loos \& Ivan 2018; Mosberg Iversen \& Wilińska 2020; Ylänne 2020). Research has examined media such as film and TV (e.g. Chivers 2019; Dolan 2017; Oró-Piqueras \& Wohlman 2016), advertising (e.g. Lamb \& Gentry 2013; Ylänne 2015; Yoon \& Powell 2012), magazines (e.g. Lumme-Sandt 2011) and online contexts (e.g. Nimrod \& Ivan 2019; Xu 2020), among others. Although images of ageing are a relatively well-explored area in ageing studies, this study contributes to existing research by offering a longitudinal examination of advertising images in a specific context. It investigates UK magazine advertising by adopting a chronologically comparative method, comparing adverts from 2011 to 2016 with those from about 10 years earlier (1999-2004) via a content analysis. As a more novel contribution to existing scholarship, this is complemented with a visual analysis that draws on Kress and van Leeuwen's $(1996,2004)$ social semiotic model to further investigate compositional 
and affective dimensions of the adverts, in addition to their distributional qualities. These will give further access to the meaning potential of the adverts in constructing aspirational imagery of later life.

Advertising forms a specific genre of media text. Cook (2001: 219-226) outlines some typical features of advertising, suggesting they "foreground connotational...and metaphorical meaning", "seek to alter addressees' behaviour", "attempt to give pleasure", "gain and hold attention, ...[and] fix a name with positive associations". Cook also proposes that "the worlds in ads are 'unreal'...they are often bland and problem-free. The families are happy; the days are sunny; the meals tasty...the grannies kind" and "[they] generally avoid the truly controversial". Exceptions are, for example, charity appeals with scenes such as war or abject poverty.

The most important categorisation process by advertisers is one by consumer, and publications targeting the "grey/silver market" have been researched in the UK at least since the 1990s (Blaikie 1999; Featherstone \& Hepworth 1995). Meiners and Seeberger (2010: 294) suggest that "seniors [are] one of the most important target consumer groups for the coming decades and ... a significant driving force for company success in many industries". They report that this consumer group is growing much faster than the rest of the adult market, and their review of the 50+ marketing literature summarises the message by marketers as "focus on feel age, not real age" (2010: 300). Indeed, as found by Sudbury and Simcock (2009) in a UK questionnaire study, consumers with a mean chronological age of 62.4 years displayed a cognitive age of 52.7 years, and marketers aim to respond to this discrepancy in their strategies. Moschis and Mathur (2006: 344) similarly demonstrate older adults' "subjective age as an explanatory variable of consumers' response to age-relevant products and age segmented marketing strategies", with "young old" consumers being reluctant to identify with such products. Kohlbacher and Chéron (2012: 185) add that the difference between chronological age and cognitive age decreases with lower levels of wealth and health. As regards older consumers' values, "the most important value ... is selfrespect, followed by security, warm relationships with others, and ... a sense of accomplishment", with fun and enjoyment in life being the fifth most important, according to Sudbury and Simcock (2009: 30). Although the order of this ranking varies between older age cohorts, the inclusion of these values in advertising is expected to be positively received. These findings 
International Journal of Ageing and Later Life

suggest hypotheses for the current study. First, we might expect at least some changes in advertising imagery over the two time periods under investigation, to reflect the increase in ageing populations as purchasers of a variety of goods, and their spending power. Increasing number of consumers might be reflected in more varied types of representations and product categories. Second, ageing is likely to be oriented to implicitly rather than explicitly in adverts (e.g. by avoiding direct reference to age in years in line with target consumers' cognitive age) and to reflect the above-mentioned values.

As Heinrichsmeier (2020) and many others (e.g. Enßle \& Helbrecht 2020) discuss, there are two predominant discourses of ageing circulating in current Western societies. One, influenced by biology, views ageing as inevitable decline (e.g. Gullette 2004, 2015) reflected in the negative stereotypes of frail, vulnerable and lonely older adults. This representation predominated in the media last century. But it continues to frame, for example, public discourse that "others" older populations, conceptualising them as a homogeneous vulnerable group (e.g. Rozanova 2006; this framing has also been evident in recent news media commentary during the coronavirus disease 2019 [COVID-19] pandemic). The second predominant discourse of ageing is different, although linked to the decline narrative. That is the discourse of "successful ageing" (e.g. Katz \& Calasanti 2015), which appears more positive in conceptualising later life as a time of renewal and new opportunities. This "third age" rhetoric is visible in advertising and in publications directed at affluent older consumers (e.g. Lumme-Sandt 2011). Appearing to frame later life with positive qualities and imagery, this discourse links with neo-liberal ideas of self-responsibility, in this case for one's health and ageing, promoting an active late lifestyle to age "well" (Ylänne et al. 2009). The promotion of "ageless" (e.g. Andrews 2018; Lamb \& Gentry 2013) extended midlife-styles also pushes the boundary of "old age" further to those in the dependent and vulnerable "fourth age" (e.g. Gilleard \& Higgs 2010). In line with the general trends in advertising mentioned earlier, it seems reasonable to expect advertising to foreground "successful ageing", whilst advertising for products offered as solutions to age-related "problems" may also draw from the decline discourse.

To investigate the depiction of older adults in UK magazine advertising, and to link the analysis with cultural gerontological concerns with 
culturally constitutive meaning of age(ing), this study will address the following research questions (RQs):

RQ1: how does a more recent sample (2011-2016) of UK magazine adverts featuring older adults compare with an earlier sample (1999-2004) regarding distribution across magazines, type of portrayal, product categories, gender distribution and advertising target?

RQ2: how is later life lifestyle depicted in these adverts?

Whilst the first RQ aims to mainly address distributional aspects of the data via content analysis, the second RQ aims to address qualitative dimensions of how the adverts link to the "successful ageing" discourse and the social imaginary of later life. However, content analysis and qualitative analysis are not mutually exclusive (Lutz \& Collins 1993, cited in Rose 2012: 90), and the typology aspect of the analysis in RQ1, for example, involves the coding of features that are potentially overlapping and require interpretation.

\section{Literature Review and Background to Study}

Under-representation of older adults in the media has been reported across the globe. For example, studies in the USA (Miller et al. 2004; Roy \& Harwood 1997), the UK (Simcock \& Sudbury 2006), Germany (Kessler et al. 2010), China (Zhang et al. 2008), Japan (Prieler et al. 2009, 2011), Hong Kong (Prieler et al. 2016), South Korea (Lee et al. 2006) and Taiwan (Chen 2015) have highlighted the scarcity of older models in the media, compared to their proportion in the population, with the exception of the study by Idris and Sudbury-Riley (2016) on Malaysian adverts. Underrepresentation is typically linked to (visual) ageism, but the qualitative and semiotic aspects of the depictions are under explored in these studies.

As regards older adults' status or prominence, where older adults do appear in adverts, they are often cast as the main characters, especially when targeting older consumers (Williams et al. 2010b). Older advertising models are found to index specific qualities of the product, such as reliability or to imply that the company represented is well established (e.g. Swayne \& Greco 1987; Williams et al. 2010a). The roles and contexts are likely to be age-marked in some way, suggesting that older characters 
International Journal of Ageing and Later Life

tend to appear in adverts for a specific reason. It is, therefore, important to examine how they are portrayed since their presence constitutes specific meanings of older age. Similarly, it is important to acknowledge in what ways older adults are typically absent.

The setting in which older models appear in adverts has also been investigated. In TV adverts in the USA, older adults have been found predominantly depicted in domestic settings (Swayne \& Greco 1987), and this is also true in older-age-targeted print adverts in the UK (Williams et al. 2010b) and TV adverts in Malaysia (Ong \& Chang 2009). But older adults also occasionally appear in business settings (Kessler et al. 2010). It has been suggested that older females are more likely to appear in domestic settings and older males in the workplace (Prieler et al. 2011). This reflects the role of advertising in sustaining not only stereotypes associated with age but also those regarding gender roles.

Food, pharmaceutical products, health aids, and financial/insurance products and services are the categories of product adverts which most often use older models in both Western and Asian contexts (Chen 2015; Prieler 2012; Williams et al. 2010b), even though some cross-cultural differences have emerged. For example, older adults do not appear in food adverts as prominently in Japan as in the West. These product associations reflect and sustain stereotypical expectations about older people as a social group. For example, food adverts might depict inter-generational family groups (where older adults feature as grandparents), and older consumers (and their families) are targeted with products aimed to alleviate various minor health- or mobility-related "problems of ageing". Some financial/insurance products are specifically marketed for the over 50s and employ older celebrity endorsers (e.g. Chen \& Ylänne 2012).

Finally, some content analytic studies code the depiction of the older adults along the dimension of its tone using a scale from very negative to very positive, for example. Roy and Harwood (1997) coded older characters in US TV adverts as regards their physical features (e.g. strong/ weak), personality traits (e.g. happy/sad and comical/serious) and cognitive abilities (e.g. lucid/confused) and found that positive portrayals predominated (see also e.g. Miller et al. 2004). However, it is not unproblematic to ascertain to what extent a portrayal is "positive" or "negative": what might be considered "positive" portrayals can turn out to be more ambiguous in their constructions of older age than appears at first sight 
(Fairhurst 2012), which a semiotic focus can help to uncover. We will return to this theme in the analysis below.

Content analysis is a method widely used in researching the mass media as it is well suited for systematically coding and analysing large data sets (Rose 2012: 82), can effectively uncover general trends and patterns and has also been used in cross-cultural comparisons (e.g. Chen 2015; Prieler et al. 2016). However, Rose (2012: 86) suggests that "it...has very little to say about the production or the audiencing of images". By "audiencing", Rose refers to "the process by which a visual image has its meanings renegotiated, or even rejected, by particular audiences" (p. 30). The composition of images and the social practices that structure the viewing - in this case, the reading/browsing of a magazine - affect the audiencing of images. I will now move onto describing another framework that is used in the analysis; one that, in taking images apart, focuses on how they make meaning, "how they work in relation to broader systems of meaning" (Rose 2012: 105), such as current discourses of (successful) ageing and how they might be read.

Kress and van Leeuwen $(1996,2004)$ offer a grammar approach to visual representation. They propose a three-way categorisation of meaning making in images: representational, interpersonal and compositional/textual, drawing on Halliday's (e.g. 2004) three metafunctions in his model of grammar.

The representational metafunction or meaning refers to images representing the world as narrative or conceptual. Narrative representations comprise action of some sort, so we could look at, for example, what type of action an older protagonist is carrying out in an advert, or whether there are any differences in the actions of older men versus older women, or the older characters versus other characters, if such are present. Conceptual representations deal with participants in terms of their more stable, essential and generalised qualities that suggest taxonomic classifications (such as a grandparent). Second, the interpersonal meaning of images relates to how depicted participants symbolically interact with the viewer through gaze, social distance and frame, and the angle of interaction. For instance, a direct gaze at the viewer establishes a "demand gaze" - a reaction is "demanded" of the viewer. In an "offer gaze", on the other hand, with no direct eye contact with the viewer, the viewer is invited to scrutinise the depicted participant(s). Differing degrees of social 
International Journal of Ageing and Later Life

distance is created via the angle of interaction: horizontal angle suggests relations of involvement, and vertical angle (e.g. looking up to the person in the image) suggests relations of power. Third, the compositional/ textual meaning refers to how "the representational and interactive elements are made to relate to each other, the way they are integrated into a meaningful whole" (Kress \& van Leeuwen 1996: 181), for example via the placement of elements in the foreground or background, left or right, centre or margin and so on, thus constructing meaning via the principles of information value, salience and framing.

Whilst content analysis allows a systematic quantification of distinct qualitative content categories, "it is not concerned with 'reading' or interpreting each text individually" (Bell 2001: 14), and therefore cannot facilitate in-depth interpretation. Semiotic analysis, in contrast, is a qualitative method aiming to answer how particular depictions - in this case of older adults - are achieved or composed. I will now describe the data and how it was collected, before moving onto the analysis. The subsequent main sections comprise the chronologically comparative analysis of the adverts in the two corpora and a semiotically oriented analysis of a subset of adverts in corpus 2 . I will conclude by discussing the findings as a contribution to research on ageing in the media.

\section{Data and Sampling}

In order to generate a representative sample of British magazine advertisements, we (Williams et al. 2010a, 2010b, corpus 1) used Brad Monthly Guide to Advertising Media (March 2004), Willing's Press Guide to U.K. Media (2003) and the National Readership Survey (NRS 2003). According to the criteria of popularity (circulation figures) and demographic readership information (aiming for a varied audience), the following magazines were selected for corpus 1 (years 1999-2004): Radio Times (home), The Economist (business), Saga Magazine (older readership), ASDA Magazine (general, home and family), Marie Claire (younger women), Rugby World (men and sport), Men's Health (men), FHM (younger men), Good Housekeeping (women, home and family), Family Circle (older, home and family) and BBC Good Food (home) (see Williams et al. 2010a, 2010b). For corpus 2 (years 2011-2016), the aim was to sample the same magazines. However, the unavailability of Rugby World and Family Circle meant leaving Rugby 
World out of corpus 2 and replacing Family Circle with Yours (having a similar readership profile). The second corpus, thus, comprised only ten magazines. As with corpus 1, hardcopy magazines were sourced from the British Library in London, complemented with the author's university library archives. To create a more manageable sample in both corpora, a single composite year was compiled using stratified random sampling, so that magazines across the different years and months were represented.

The resultant 121 magazine issues (corpus 1) and 116 issues (corpus 2) were scrutinised for any advertisements quarter of a page and larger, containing a recognisable human figure appearing to be 60 years of age or older (on the basis of visible signs of ageing, such as grey hair, wrinkles and possible older-age salient features in the environment and/or text). This resulted in an initial total of 253 adverts (corpus 1) and 479 adverts (corpus 2) with an older person featured as one or more characters in the adverts found in the sample magazines. From these, duplications were eliminated, and this resulted in final corpora of 221 advertisements (corpus 1) and 313 advertisements (corpus 2). Although discarding duplicate adverts admittedly erases the effect of repeated exposure to images, this was motivated by the original aim to capture the types and categories of portrayal, rather than, for example, to investigate the frequency of representation of older versus younger adults. I will now proceed to the data analysis.

\section{Content Analysis: Earlier Versus Later Corpus Distribution of Adverts across Magazines}

As can be seen in Table 1, the vast majority of the adverts in both corpora featured in the 50+ targeted Saga Magazine, as well as Yours (corpus 2), also with an older readership. The decline in the number of adverts in Saga in corpus 2 is partly explained by a large number of duplicate adverts (only counted once). FHM, Marie Claire and Men's Health magazines whose readership tends to be under 35 years continue to have very few adverts depicting older adults.

\section{Product Categories}

In corpus 1 , the most frequently advertised products overall were help and support aids, such as mobility aids, stairlifts, walk-in baths and showers 
International Journal of Ageing and Later Life

Table 1. Distribution of adverts across the magazines

\begin{tabular}{lcccc}
\hline Magazine & Nin corpus 1 & $\%$ & N in corpus 2 & $\%$ \\
\hline Saga Magazine & 137 & 61.9 & 138 & 44 \\
BBC Good Food & 13 & 5.8 & 28 & 8.9 \\
Good Housekeeping & 12 & 5.4 & 21 & 6.7 \\
Radio Times & 12 & 5.4 & 32 & 10.2 \\
Family Circle & 10 & 4.5 & N/A & \\
FHM & 10 & 4.5 & 3 & 0.9 \\
Economist & 10 & 4.5 & 9 & 2.8 \\
Marie Claire & 8 & 3.6 & 10 & 3.2 \\
Rugby World & 4 & 1.8 & N/A & \\
Asda Magazine & 3 & 1.4 & 11 & 3.5 \\
Men's Health & 2 & 0.9 & 8 & 2.6 \\
Yours & $\mathrm{N} / \mathrm{A}$ & & 53 & 16.9 \\
Total & 221 & & 313 & \\
\hline
\end{tabular}

(26.2\% of the total). The next most frequent category was medical and health products $(14.5 \%)$ and food and drink $(14 \%)$, followed by retirement housing $(8.1 \%)$ and household items $(8.1 \%)$. Cosmetics, hygiene, and grooming products $(4.1 \%)$ and charities $(4.1 \%)$ were infrequent, as were clothing $(3.2 \%)$ and professional/expert services (3.2\%). Miscellaneous consumables $(1.4 \%)$ and education $(0.9 \%)$ were also infrequent. The most infrequently encountered products were final arrangements and holidays (both $0.5 \%$ ).

In corpus 2, the most frequently advertised products were again help and support aids (15.3\%), followed by medical and health products (14.4\%). But this time retirement housing was the third most prominent group (13.1\%), followed by food and drink (9.6\%). Whereas cosmetics and financial/insurance products were almost as frequently present in the two corpora, the number of adverts for holidays had increased in corpus 2 (from 0.5 to $6.1 \%$ ) as had the number of adverts for funeral plans (from 0.5 to $3.2 \%$ ). Charity adverts had declined in corpus 2, as had those for household items and professional expertise. Table 2 summarises the results for the two corpora. The relative number of adverts overall had increased from an average of 1.83 adverts per magazine issue in corpus 1 to 2.7 per issue in corpus 2 . 
UK magazine advertising portrayals of older adults

Table 2. Products associated with older models across the magazines

\begin{tabular}{lcccc}
\hline Product type & $N$ in corpus 1 & $\%$ & $N$ in corpus 2 & $\%$ \\
\hline Help and support & 58 & 26.2 & 48 & 15.3 \\
Medical/health & 32 & 14.5 & 45 & 14.4 \\
Food and drink & 31 & 14.0 & 30 & 9.6 \\
Retirement housing & 18 & 8.1 & 41 & 13.1 \\
Household & 18 & 8.1 & 17 & 5.4 \\
Entertainment (media, electronics, etc.) & 13 & 5.9 & 14 & 4.5 \\
Financial insurance & 12 & 5.4 & 20 & 6.4 \\
Cosmetics/hygiene/grooming & 9 & 4.1 & 15 & 4.8 \\
Charities & 9 & 4.1 & 9 & 2.9 \\
Clothing & 7 & 3.2 & 15 & 4.8 \\
Professional expertise & 7 & 3.2 & 7 & 1.9 \\
Funeral plans & 1 & 0.5 & 10 & 3.2 \\
Holidays & 1 & 0.5 & 19 & 6.1 \\
Education & 2 & 0.9 & 6 & 1.9 \\
Other & 3 & 1.4 & 17 & 5.4 \\
Total & 221 & & 313 & \\
\hline
\end{tabular}

Table 3. Gender distribution in adverts

\begin{tabular}{lcccc}
\hline Gender distribution & $N$ in corpus 1 & $\%$ & $N$ in corpus 2 & $\%$ \\
\hline Female & 90 & 40.7 & 127 & 40.6 \\
Male & 63 & 28.5 & 87 & 27.8 \\
Both & 68 & 30.8 & 99 & 31.6 \\
Total & 221 & & 313 & \\
\hline
\end{tabular}

\section{Gender Distribution in Advertisements}

The distribution of gender in the magazine adverts in the two corpora was practically identical (see Table 3 ). Just over $40 \%$ of all adverts depict older women, either as single images or in groups; about $28 \%$ depict only men and about $31 \%$ both men and women. 
International Journal of Ageing and Later Life

\section{Rhetorical Schema}

Thimm's (1998) German research classified images of older people in advertising along four dimensions (rhetorical schemas) that consider the target audience and the overall imagery of the advert. These were labelled age inclusive, age exclusive, age contrastive and age preferential. The first includes adverts targeted at all age groups, whereas age exclusive adverts are aimed at older adults only. Age preferential adverts are likely to be of more interest to older than to younger people (because of the product and the general tone of the advert). Age contrastive adverts, in turn, draw a direct or indirect contrast between younger and older adults in ways that tend to (but do not always) portray older people more negatively, typically in adverts targeting younger audiences. Thimm's classification system was applied to the UK data, but the category "age inclusive" was replaced with "age incidental", in which the product is not targeted at a specific age group and which does not use the character's age as a selling point. Table 4 presents the findings regarding the two corpora on this aspect of the analysis.

Whereas the proportion of age exclusive adverts has remained at a similar level, age preferential adverts have increased. Both age incidental and age contrastive adverts have decreased over the years. In corpus 1 , out of the 86 age exclusive adverts, ten $(12 \%)$ made direct reference to chronological age. In corpus $2,28(25 \%)$ of such adverts included a reference to age-in-years. In both corpora, these were typically adverts for health and support products, insurance (e.g. life insurance) or medical procedures or

Table 4. Rhetorical schema in adverts

\begin{tabular}{lcccc}
\hline Rhetorical schema & $N$ in corpus 1 & $\%$ & $N$ in corpus 2 & $\%$ \\
\hline Age exclusive & 86 & 38.9 & 114 & 36.4 \\
Age preferential & 54 & 24.4 & 118 & 38.0 \\
Age incidental & 68 & 30.8 & 70 & 22.4 \\
Age contrastive & 13 & 5.9 & 8 & 2.2 \\
Other & 0 & 0 & 3 & 0.95 \\
Total & 221 & & 313 & \\
\hline
\end{tabular}


drug trials. As discussed earlier, age-targeted advertising tends to refer to age in more implicit ways, either by reference to "retirement" or through various visual indices of age. We will return to these in the following semiotically oriented analysis.

\section{Typology}

Hummert and colleagues' $(1994,2004)$ research (in the USA) has uncovered a range of positive and negative stereotypes of older people. In their taxonomy, positive stereotypes held by people of all ages consist of the "perfect grandparent" (a kind, loving and family oriented older adult), the "golden ager" (lively, adventurous and alert) and "John Wayne conservative" (patriotic, religious and nostalgic). The four negative stereotypes are the "despondent" (depressed, sad and hopeless), the "shrew/ curmudgeon" (complaining, ill-tempered and bitter), the "recluse" (quiet, timid and naïve) and the "severely impaired" (slow-thinking, incompetent and feeble). It can be predicted that in advertising, in the pursuit of positive associations with the product, positive stereotypes predominate, unless the advert aims to evoke sympathy or fear, for example.

Williams et al. (2010a) aimed to inductively devise a typology of adverts depicting older adults, although some of the resultant labels echo Hummert's category labels. The adverts in corpus 1 were investigated to determine the main thematic portrayals, which was done via an iterative process of sorting and re-sorting the adverts into similarity types. This was repeated until the researchers arrived at a set of themes that adequately described the entirety of the portrayals in the data set, and a satisfactory inter-coder agreement was reached, complemented by a discussion of differences in coding. A thematic typology of six image types of older adults was proposed. The "golden-ager" describes older people who are youthful and full of zest, often having luxurious lifestyles. "Perfect grandparents" are older people shown with grandchildren, often closeups of smiling and happy families, sometimes depicting several generations. "Legacy" theme refers to older persons with "gravitas" and status, often mentor types with implied experience and wisdom, and these were almost exclusively males rather than females. "The coper" is an older person who has a problem, such as a mobility limitation, but is coping with 
International Journal of Ageing and Later Life

Table 5. Typology of depictions

\begin{tabular}{lcccc}
\hline Type & $N$ in corpus 1 & $\%$ & $N$ in corpus 2 & $\%$ \\
\hline Golden ager & 79 & 35.7 & 96 & 30.7 \\
Coper & 53 & 24 & 85 & 27.2 \\
Mentor/legacy & 32 & 14.5 & 26 & 8.3 \\
Celebrity endorser & 22 & 10 & 46 & 14.7 \\
Perfect grandparent & 17 & 7.7 & 29 & 9.3 \\
Comedic & 13 & 5.9 & 2 & 0.6 \\
Other & 5 & 2.3 & 29 & 9.3 \\
Total & 221 & & 313 & \\
\hline
\end{tabular}

it because of the product being sold. "Comedic" older people are those depicted in humorous situations and/or poses. "Celebrity endorsers" are well-known older adults in the public eye who endorse the advertised product. The six types from this analysis were offered as candidates for a typology of advertising images of older adults, at least within a British context, and the present study investigated its applicability for corpus 2 . Table 5 presents the results of this part of the analysis.

It appears that the "golden ager" type depiction is still the most common. This is specifically the case in older-targeted advertising, such as that in Saga Magazine and Yours. The prevalence of "coper" types has remained high, and celebrity endorsers have increased slightly, as have grandparent depictions. The mentor/legacy type has decreased, and, most notably, corpus 2 has hardly any examples of humorous depictions. The slight differences in the magazines sampled might be one reason for this latter difference. A possible reason for advertisers now avoiding humorous depictions of older adults is because these typically rely on negative ageist stereotypes, which make older adults look (literally) "laughable". It can also be noted that $9 \%$ of adverts this time round were coded as "other", suggesting that the earlier typology no longer fully captures the types of portrayals.

The adverts in the "other" category in corpus 2 fell into different groups. Most included an older adult or a couple (male and female) who were healthy, sometimes active, but who looked less glamorous and whose 
surroundings were less luxurious than golden agers'. Others included a picture of an older adult among adults of various ages, providing a wider age range of imagined consumers for the advertised product. Yet others focused on family and intergenerational relations, but the older characters signified parents, not grandparents. I will now move onto the social semiotically oriented analysis, especially to answer RQ2.

\section{Social Semiotically Oriented Analysis}

As discussed earlier, a content analysis of adverts provides some overall patterns in the portrayal and shows in what contexts we might see older characters in advertising. A more nuanced picture of how the depictions are achieved in terms of what choices are made in the design of the adverts can be obtained via a social semiotic lens, building on the compositional aspects coded for the content analysis. Van Leeuwen (2005: xi) explains that "in social semiotics the focus... [is] the way people use semiotic 'resources' both to produce communicative artefacts and ... to interpret them". According to Jewitt and Oyama (2004: 136), social semiotics is "a tool for use in critical research", and Rose (2012: 106-107) links semiotic approaches with those seeking to understand the working of ideologies. Similarly, in this study, the social semiotically oriented analysis seeks to link the advertising images with current discourses of ageing, in particular "successful ageing", and to examine what strategies advertisers use to imply or connote certain interpersonal relations and what techniques of design are used to involve the reader with the image. As adverts for retirement housing were the third most prominent category in corpus 2 , and the category which had increased notably over time, I will focus on the 41 retirement housing adverts in this later corpus for this closer analysis.

The representational meanings will be analysed in terms of "who are the residents in these dwellings" (conceptual categorisation), by focusing on what narratives emerge via the actions depicted. The compositional meanings, on the other hand, will give access to the setting of the participants, the most salient objects and, for example, the centrality of the older adults in the visuals. The interpersonal meaning will relate to the angle of the picture and how the viewer is positioned. These aspects could arguably also be approached from a content analytic perspective, but we will 
International Journal of Ageing and Later Life

approach the adverts socio semiotically in terms of the symbolic links they make with later life and the meaning potential that is designed to be activated in the viewers. Overall, the focus is on the construction of implied "positivity" in the adverts (their selling point), in addition to what activities the older characters are depicted as doing. I first offer an overview of this group of adverts.

\section{Representational Meanings}

Most protagonists in the images are depicted as couples or small groups. The activities include having refreshments (such as orange juice, tea/coffee and food such as cakes or salad) in the garden. The participants are seemingly enjoying each other's company and in conversation. In some adverts, residents appear to be visiting each other's apartments, connoting friendly communal relations. Couples (a man and a woman) are also featured walking, cycling or walking their dog outdoors. In only three adverts, the older characters are positioned as grandparents interacting with family, for example having a birthday party. It is the life within and around the residence that is typically the narrative setting.

\section{Compositional Meanings}

The older characters are depicted sitting down more often than standing or moving. The setting is as often outdoors as it is indoors, with only eight consisting of a neutral, blank studio setting. In the majority of the pictures, the older adults are central, sharing the focus with younger characters in only nine adverts. In slightly over half of the adverts, the older characters are smiling. The most common objects surrounding the protagonists are those linked with the activity of drinking and eating, such as tea/coffee cups and saucers, glasses of orange juice, cake, bowls of fruit, wine glasses and bottles. Other objects relate to activities such as reading (newspapers, books and reading glasses), walking (walking stick), going to the gym (gym equipment) or the setting (garden furniture, roses and sunhat). Indices of relative wealth, age, and standard of living and taste include aspects of the protagonists' attire (stylish scarves, jewellery, grey and light-coloured clothing to match the colour of a person's grey or white hair and lipstick), delicate china and well-appointed communal dining rooms. 
UK magazine advertising portrayals of older adults

\section{Interpersonal Meanings}

The horizontal angle of viewer positioning is almost exclusively fully frontal, suggesting a relation of involvement between the viewer and the character(s). In only ten adverts, there is a direct gaze ("demand") towards the viewer. The relational distance between the protagonists and the viewer tends to be constructed via close or medium close rather than long shots.

Bell (2001: 34) proposes that "research adopting [content analysis] should supplement and extend its findings by means of detailed analysis of typical examples". To do this, I now give two examples of these types of adverts. Since copyright restrictions prevent showing the original adverts, they were traced to give a sketch of how they looked on the page of the magazine.

\section{Example 1}

In example 1 (see Figure 1), the image is an "offer" for the viewers' gaze. The central focus of this gaze is the narrative action of the two females' seemingly enjoyable talk and interaction over a "cuppa". They are gazed at by the male, whose gaze forms a vector (Kress \& van Leeuwen 1996: 44), shared by the viewer, towards the women and their joined laughter and mutual eye contact. The women sit next to each other on a well upholstered sofa. The action is socialising, also confirmed by the prominent text in the left-hand corner of the picture - "Because friendship matters...". The women are, thus, conceptually to be understood to be friends, not mere fellow residents in the same apartment complex. The other accompanying text underneath a row of outdoor shots of these apartments reiterates the theme of social activities ("Owners' Lounge where you can meet new friends"), whilst also mentioning independence. A medium close shot photo in the bottom left-hand corner is of the named company chairman, with a direct gaze (and thus address) at the viewer, with the accompanying text: "Now is the time that you should be enjoying life... you will experience the Independence, Security and Peace of Mind that comes with choosing an award-winning retirement development company". The text and photo in the lower part of the page serves to elaborate the ideologically foregrounded top part of the page, occupied by the main image (cf. Kress \& van Leeuwen 1996: 194). 
Figure 1. Example 1

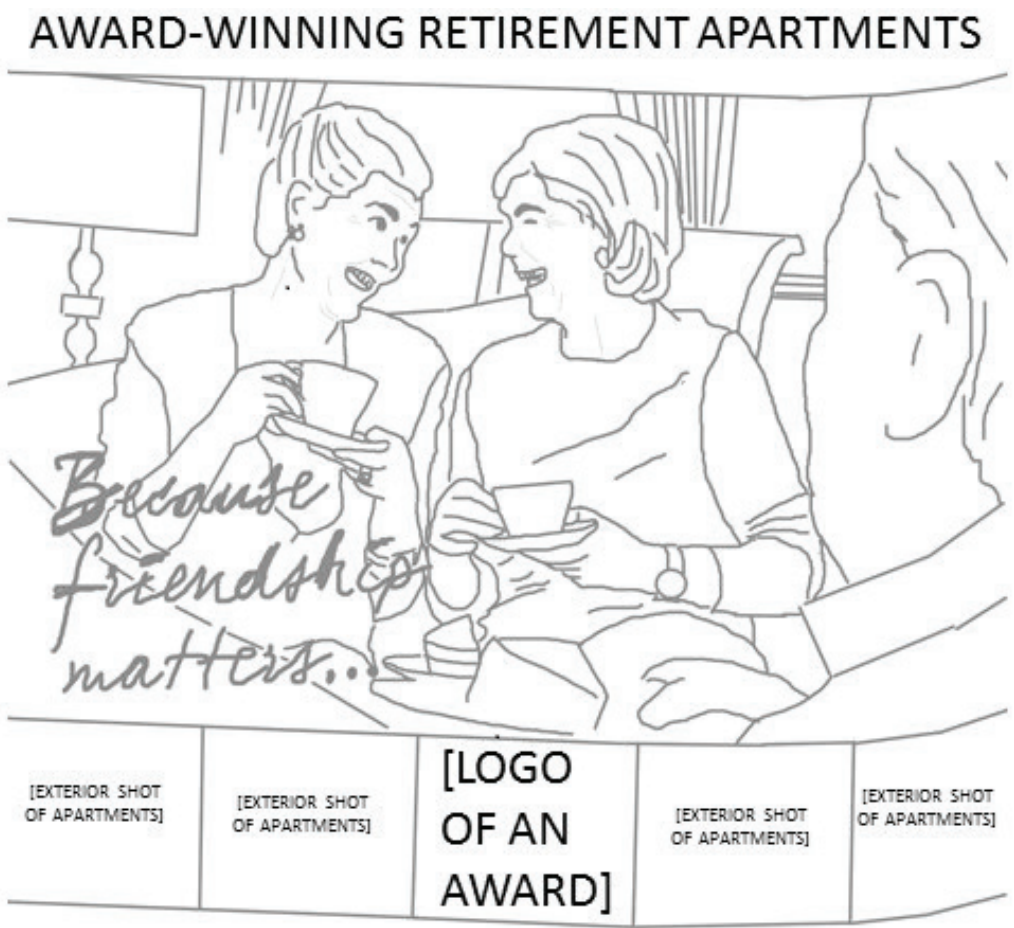

...you'll want the best in retirement living

[small text] [small text] [small text] [small text]

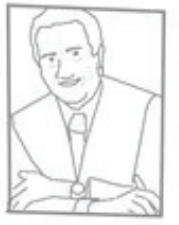

[small text]

[small text]

[small text]

[small text] [small text]

[signature]

[BRAND LOGO]

Enjoy Independence and Peace of Mind in Your Retirement 
The inference the reader can make of this advert is that the housing provides a solution to potential social isolation, a sense of vulnerability, as well as providing an independent living arrangement and the prospect of "enjoying life". The advert, and others like it, seems to be trying to balance these somewhat conflicting and potentially challenging aspects of later life. There are various indices of wealth and luxury in the image, such as the style of the furnishings, the protagonists' attire and the soft, muted colours of gold, beige and pale orange in the room and rhymed in the visible clothing. The composition places the image and theme of friendship in a prominent position and that is the main construction of positivity here. The medium close shot of the residents creates an interactive meaning of "far personal distance" (Kress \& van Leeuwen 1996: 130), bringing the target audience into an imagined acquaintance relation with the protagonists. Regarding the values reportedly being important for older consumers (Sudbury \& Simcock 2009), security and warm relationships with others, together with fun and enjoyment, are connoted by the prominent image in this advert.

\section{Example 2}

Example 2 (see Figure 2) most likely uses a stock photo from an image bank of a couple cycling, with the male in the lead and the female just setting out on her bicycle behind him. The male is looking ahead, and the female is looking at the male, both smiling. The man is in a clearer focus than the woman, and the background behind her is blurry greenery and trees, suggesting a parkland setting. The couple appear as exemplars of those "young-at-heart", a reference in the red text on white on the right-hand side. The image on the left of the main text signifies "given" information (already "known" to the reader), with the text, being on the right-hand side, the "new" information, the "message" (Kress \& van Leeuwen 1996: 186), associating the referents with the company/housing. Positioning the picture at the top half of the advert indexes the imagined "ideal", the "promise of the product" (Kress \& van Leeuwen 1996: 193). The physical activity of the couple and reference to youthfulness provide the basis of the implied positivity in this advert, strengthened, for example, by the casual colourful clothing and jeans worn by both protagonists. The colour palette of the main picture is fresh, constituted by turquoise, 
Figure 2. Example 2

\section{AWARD-WINNING RETIREMENT APARTMENTS}

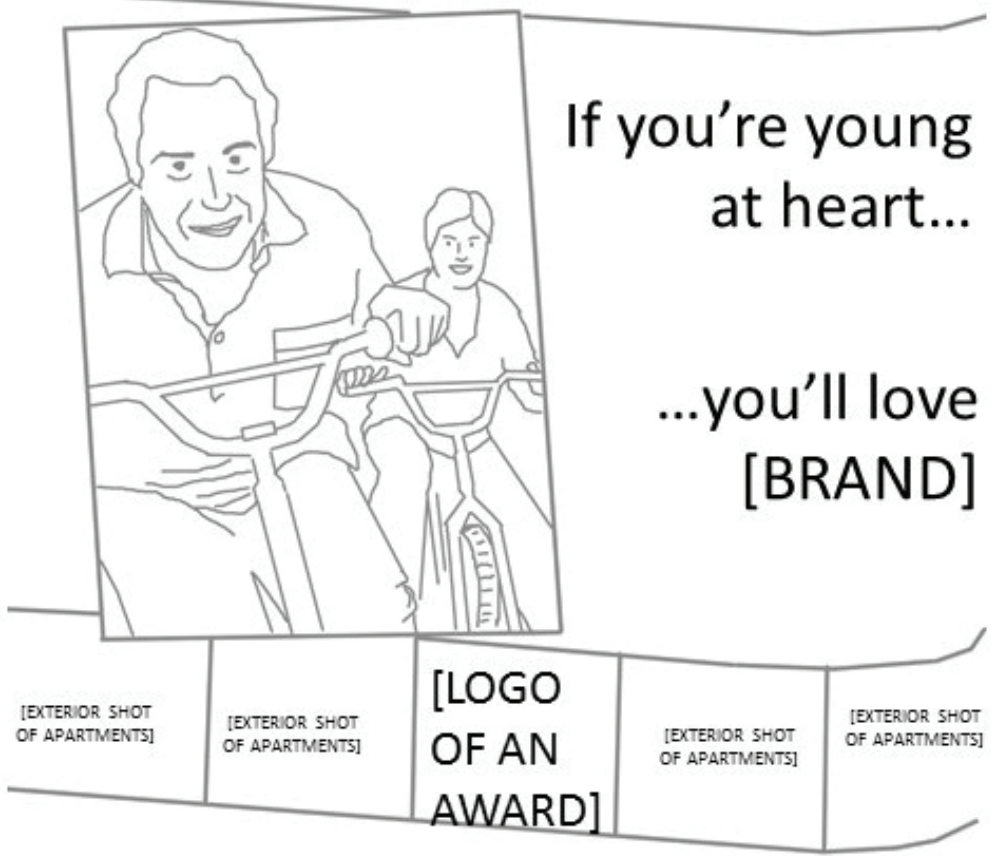

Love Independence. Love Safety. Love Security.

[small text] [small text] [small text] [small text]

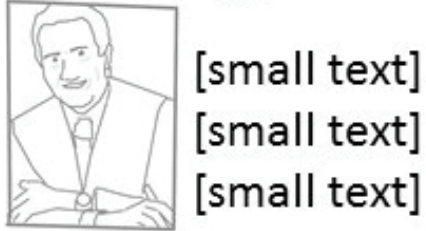

[signature] [small text] [small text]

$$
\begin{gathered}
\text { [price range] } \\
\text { Request a brochure on } \\
\text { [phone number] } \\
\text { [web url] }
\end{gathered}
$$

[BRAND LOGO]

Enjoy Independence and Peace of Mind in Your Retirement 
pink and indigo in the couple's clothes, and this high modality contributes to the affective meanings of the image (Kress \& van Leeuwen 1996: 170). The couple are both tanned, fitting the summer setting. The value of fun and enjoyment (Sudbury \& Simcock 2009) is foregrounded in this advert via the main image. Although there is no visual demand "you" via direct gaze, there is a textual repeated address of "you" for the reader. The text underneath the picture elaborates the selling points of the apartments and addresses potential buyers' age-related concerns about safety and security, in addition to independence (as in example 1).

Besides being age-targeted images of retirement housing, the adverts constitute specific gender roles, too. In both examples, we can see gender stereotypes at play: the females in example 1 are socially engaged in conversation (in friendly gossip?), and in example 2, the woman is following the man, who is taking the lead. Advertising texts and images have the power to normalise certain types of representations. In general, it seems that older age-targeted advertising tends to offer conventional scripts about coupledom.

In the retirement housing adverts, later life lifestyle (cf. RQ2) is constructed in particular ways, foregrounding a lifestyle where the residents are using communal spaces indoors and outdoors to socialise with other residents over seemingly endless cups of tea/coffee/wine and dinners, in their pursuance of independent, yet socially connected lives. For example, in one such advert, depicting a woman sitting, knees bent, on a sofa and reading a book, we read "The countless coffee mornings, afternoon teas, flower arranging, book clubs, keep fit, garden parties and charity events will be sure to keep you busy. And after all that, you can just put your feet up with a good book! Enjoy independence or companionship - the choice is yours". In looking after their health (signified by occasional gym and gardening shots), diet and friendships/ relationships, the older adults are presented as pursuing leisure and social relations with other residents. They are portrayed as independent but not lonely, living in their own apartment but not isolated and active but only in a domestic or leisure setting. Interestingly, the activities do not seem to include interacting with media (e.g. social media to connect with others, cf. Kivimäki 2017). The context of the retirement housing adverts needs to be acknowledged, as the majority appeared in Saga Magazine, whose readership tends to be relatively affluent. They are, therefore, more likely than readers in lower socio-economic groups to identify with the depicted settings and imagery. 
International Journal of Ageing and Later Life

\section{Discussion and Conclusions}

To answer RQ1, this study found only minor differences between adverts depicting older adults in UK magazine advertising between the two time frames. The sixfold typology (Williams et al. 2010a) appears still fairly, but not wholly applicable for categorising adverts in the 21st century. We can detect some blurring of boundaries in that the "golden ager" depictions do not now uniformly consist of glamorous images, but rather fit and healthy older adults more generally. This links with the social imaginary of the third age in foregrounding activity and healthy lifestyles. It also both reflects and helps maintain the reported discrepancy between cognitive and chronological age, especially among affluent third agers. The "coper" category seems to have lost many negative aspects of representation - these are more typically now smiling images, not helpless images, again promoting the idea of self-care and responsibility. The mentor/legacy types have declined in number, and the comedic representations seem to have practically disappeared.

No notable differences emerged regarding the gender distribution of the older protagonists. Product categories were very similar in the two corpora, too: adverts for retirement housing and holidays have increased, and adverts for food and drink have decreased. Whilst the proportion of age exclusive adverts has remained constant, age preferential adverts (those most likely targeting older adults) have increased, and both age incidental and age contrastive adverts have decreased over time (in the magazines sampled). Most magazine adverts using older models, then, seem to be designed for older consumers, and increasingly focus on lifestyle advertising (housing and holidays), whilst also maintaining a focus on health-related products. Adverts in magazines targeting younger adults continue to include very few images of older adults, which points to visual ageism in this context.

"Positivity" in advertising representations of older adults is achieved via an emphasis on coupledom, communality, health and fitness, and active pursuance of addressing perceived problems of ageing (minor mobility and health issues). Grandparenting is also positively depicted, and family networks also create positive connotations. There is a preponderance of smiling images in these data, presumably designed to have a positive effect on the viewer, and this is not surprising in an advertising 
context, as noted earlier. Against these potentially appealing qualities, we need to acknowledge, though, that the activities engaged in by the older protagonists tend to be limited to daily personal and domestic activities, socialising, leisure pursuits or acting in a grandparent role. Thus, the roles and activities are limited, and the representations marginalise older adults in that we only see them in certain contexts. Interestingly, the mentor type portrayals have decreased over time. Older adults as experts do feature, but these are mostly in food-related contexts, continuing the domestic theme. Apart from a well-known older British female celebrity cook, expert roles are typically occupied by men in these data.

In terms of RQ2, the later life lifestyle in the retirement housing adverts is presented as achievable, for example via the predominantly medium close shots of the residents, involving the reader at a horizontal, full frontal angle as acquaintances. This is designed to increase the potential for readers to relate to the images. The modality (degree of "realness") ranges from relatively low (e.g. via blank studio backgrounds to images) to high (vibrant colours), and thus the degree of "truthfulness" of the depictions varies. Most images contain enough detail and "naturalness" to be relatable for the target audience, yet the poses of the protagonists can look staged. Ledin and Machin (2019) analysed the changing depictions of IKEA (Swedish multinational ready-to-assemble furniture retailer) kitchens in the company's brochures over time, and they observe a change from representing this part of the home as a separate, "functional" space in the 1970s to a "creative" space integrated into the home in 2016. A link is made by the authors between the changing conceptualisation of the kitchen/domestic space and neoliberal ideology. The representations have become more and more "codified, with increasing prescription over the meaning of space and also...what takes place there" (Ledin \& Machin 2019: 165). Such coding aligns with ideas, values and identities, including self-management. Similarly, we can see a prescription of a specific kind of third age later lifestyle and use of space in retirement housing advertising.

Hanson (2001) makes the point that over $80 \%$ of older adults in the UK live in a "normal" mainstream family house (often a two-storey house, although some older adults move to a bungalow). Whilst there has been a decrease in local authority residential provision, private sector housing schemes have increased - this likely explains the increase in retirement housing adverts. These sometimes emulate US style retirement villages. 
International Journal of Ageing and Later Life

What distinguishes these from houses in a normal residential street is that the age-profile of residents is much more homogeneous. Hanson (2001) suggests that this recent housing trend is worrying in that it results in self-segregation of affluent older adults, which negatively impacts on the composition of future communities. It is noticeable in the retirement housing adverts that very few depict interactions involve people younger (or older) than the residents. The residents are rarely portrayed as grandparents or as members of larger families. This seems to echo the segregation Hanson identifies. Perhaps the luxury retirement apartment complexes offer diminished opportunities for intergenerational mixing. The residents are depicted as free from family and work commitments.

But to what extent are these adverts representations of "agelessness" (cf. Andrews 2018; Fairhurst 2012)? Even though they do not tend to refer to the third age residents via explicit age categories (such as "housing for the over $60 \mathrm{~s}$ ", although "retirement" is mentioned), the commodity advertised is age marked, with the models appearing to be over 60 , and the selling points being implicitly age salient. Age is not, therefore, erased but purposefully packaged. Retirement housing adverts voice loneliness and insecurity/vulnerability as implicitly age-related concerns, whilst framing the advertised locations as attractive safe havens for care-free, secure and socially engaged (with people of similar age) retirement lifestyle in a new community of likeminded retirees. In other product adverts using older models, implied "problems of ageing" besides loneliness are presented as ones that can be successfully managed. These centre around mobility and relatively minor health problems, such as those relating to hearing, failing eyesight or personal care.

Timonen (2016: 78) proposes that we now have models of "very specific, normatively driven social constructs of 'ageing well and appropriately"'. These are seen in advertising, amongst other form of public discourse. More and more agency is attributed to all older adults: "model ageing notions systematically advantage older adults with specific qualities (such as good health, driven personality, extensive social networks), in specific circumstances (for example, in good-quality housing and safe neighbourhoods); in other words, individuals who are already...likely to enjoy social, health and economic advantages as they age" (p. 79). Third age marketing and advertising are part of this perpetuation of an advantage: those who are already ageing "successfully" are encouraged to do so 
in specific ways and are targets of product and lifestyle advertising that promote active, even if not completely "ageless" behaviours. As Pickard (2016: 191) suggests, "in these ads greater chronological age is linked to maturity and freedom, an elegant sexuality, a moneyed savoir-faire. This, of course, is not 'old age' but privilege". Independence and self-care are prominent themes in these data, too. Yet, as shown earlier, the "agelessness" in this imagery can be questioned, as specific models for ageing "appropriately" at retirement age are offered.

Although the imagery of active and healthy "golden agers" appears positive, it arguably promotes idealistic notions of individual responsibility in the management of the ageing process. Age-related limitations and risks are constructed as problems for which consumerised solutions are provided via help and support products, as well as (semi-) independent housing solutions, for example. Although it is important to approach advertising as a specific genre with specific promotional aims and priorities, it is notable that little variety in ageing "successfully" or in lifestyles is featured in UK magazine advertising (Ylänne 2015, 2020). Older adults might be portrayed in more varied ways in other types of advertising. But in magazine adverts, older adults continue to be depicted in limited ways that predominantly promote "stylised ageing". It is also evident that the images almost exclusively represent white demographics, erasing any ethnic heterogeneity of the "ideal readers". Couples are depicted as heterosexual; in adverts with two females (never two males), they seem to be positioned as friends (as in example 1 earlier). Only in a few adverts is the relationship status more ambiguous (albeit there is no physical contact).

Research on portrayals of older adults in the media, including advertising, has spread over the past few decades across the world. This study contributes to this area of work via its longitudinal focus, investigating persistent trends in advertising portrayals of older adults over almost two decades, and by contextualising the depictions within advertising genre and the target audience, as well as by linking its findings with current discourses of ageing. In addition, it used a methodology that captures both changing trends and offers more in-depth analysis, which can usefully contribute to cultural gerontological theorising about ageing and its representation. The combination of content analysis and (social) semiotic analysis can help us to critically approach representations of ageing, including "successful ageing" and supposedly "ageless" representations in 
International Journal of Ageing and Later Life

contemporary visual media, as shown by this study. A critical linguistic focus on advertising discourse (language) and its construction of ageing would usefully expand this study to examine the interplay between the visual and the linguistic elements. Since age intersects with other aspects of social identities, such as gender, sexuality and ethnicity, more research is needed to uncover patterns in media portrayals of these, too, in later life. Audience research, in turn, can uncover the interpretation of the meaning potential of adverts by the target audience and others.

\section{Ethical statement}

As the materials were publicly available, no ethics permissions were required. Copyright permissions to reproduce adverts have not been sought.

\section{Acknowledgements}

I wish to thank Gerard O'Grady, Elisabeth El Refaie and two anonymous reviewers for their useful comments on an earlier draft. I also thank my co-authors of the previous study (data corpus 1), Angie Williams, Paul Mark Wadleigh and Chin-Hui Chen, for their contribution, and I thank Dorottya Cserzö for her valuable help with data coding and tracing the example adverts.

\section{Corresponding Author}

Virpi Ylänne, Centre for Language and Communication Research, John Percival Building, Colum Drive, Cardiff University, Cardiff, CF10 3EU, Wales, UK. Email: Ylanne@cardiff.ac.uk.

\section{References}

Andrews, M. (2018). The seduction of agelessness, Take 2. Generations $41(4): 75-82$.

Bell, P. (2001). Content analysis of visual images. In T. van Leeuwen \& C. Jewitt (eds.), The Handbook of Visual Analysis (pp. 10-34). London: Sage.

Blaikie, A. (1999). Ageing \& Popular Culture. Cambridge: Cambridge University Press. 
Blaikie, A. \& Hepworth, M. (1997). Representations of old age in painting and photography. In A. Jamieson, A. Harper \& C. Victor (eds.), Critical Approaches to Aging and Later Life (pp. 101-117). Buckingham: Open University Press.

BRAD (British Rates And Data) Monthly Guide to Advertising Media (2004). London: Emap Information.

Chen, C.-H. (2015). Advertising representations of older people in the United Kingdom and Taiwan: A comparative analysis. The International Journal of Aging and Human Development 80(2): 140-183.

Chen, C.-H. \& Ylänne, V. (2012). Consumerism v. constructing older age: A case study of over-fifties life insurance TV advertising. In V. Ylänne (ed.), Representing Ageing. Images and Identities (pp. 36-52). Basingstoke: Palgrave Macmillan.

Chivers, S. (2019). What's exotic about The Best Exotic Marigold Hotel? Cinema, everyday life and the materialisation of ageing. In S. Katz (ed.), Ageing in Everyday Life. Materialities and Embodiments (pp. 83-98). Bristol: Policy Press.

Cook, G. (2001). The Discourse of Advertising (2nd ed.). London \& New York: Routledge.

Dolan, J. (2017). Contemporary Cinema and "Old Age". Gender and the Silvering of Stardom. London: Palgrave Macmillan.

Enßle, F. \& Helbrecht, I. (2020). Understanding diversity in later life through images of old age. Ageing \& Society 40: 1-20. doi: 10.1017/ S0144686X20000379

Fairclough, N. \& Wodak, R. (1997). Critical discourse analysis. In T. A. van Dijk (ed.), Discourse as Social Interaction (pp. 258-284). London: Sage.

Fairhurst, E. (2012). "Positive images" and calendars: Explorations in "agelessness" or "ambiguous" identities? In V. Ylänne (ed.), Representing Ageing: Images and Identities (pp. 189-206). Basingstoke: Palgrave Macmillan.

Featherstone, M. \& Hepworth, M. (1995). Images of positive ageing: A case study of Retirement Choice magazine. In M. Featherstone \& A. Wernick (eds.), Images of Ageing: Cultural Representations of Later Life (pp. 29-47). London: Routledge.

Gilleard, C. \& Higgs, P. (2010). Ageing without agency: Theorizing the fourth age. Aging and Mental Health 14(2): 121-128. 
International Journal of Ageing and Later Life

Gullette, M. M. (2004). Aged by Culture. Chicago \& London: The University of Chicago Press.

Gullette, M. M. (2015). Aged by culture. In J. Twigg \& W. Martin (eds.), The Routledge Handbook of Cultural Gerontology (pp. 21-28). Abingdon: Routledge.

Halliday, M. A. K. (2004). An Introduction to Functional Grammar. London: Arnold.

Hanson, J. (2001). From sheltered housing to lifetime homes: An inclusive approach to housing. In S. Winters (ed.), Lifetime Housing in Europe (pp. 35-57). Leuven: Katholieke Universiteit Leuven.

Heinrichsmeier, R. (2020). Ageing Identities and Women's Everyday Talk in a Hair Salon. London: Routledge.

Higgs, P. \& Gilleard, C. (2020). The ideology of ageism versus the social imaginary of the fourth age: Two differing approaches to the negative contexts of old age. Ageing $\mathcal{E}$ Society 40(8): 1617-1630. doi: 10.1017/ S0144686X19000096 14

Hummert, M. L., Garstka, T., Ryan, E. B. \& Bonnesen, J. L. (2004). The role of age stereotypes in interpersonal communication. In J. F. Nussbaum \& J. Coupland (eds.), Handbook of Communication and Aging Research (2nd ed., pp. 91-114). Mahwah, NJ: Lawrence Erlbaum.

Hummert, M. L., Garstka, T., Shaner, J. L. \& Strahm, S. (1994). Stereotypes of the elderly held by young, middle-aged and elderly adults. Journal of Gerontology: Psychological Sciences 49: 240-249.

Idris, I. \& Sudbury-Riley, L. (2016). The representation of older adults in Malaysian advertising. The International Journal of Aging and Society 6(3): 1-19.

Jewitt, C. \& Oyama, R. (2004). Visual meaning: A social semiotic approach. In T. van Leeuwen \& C. Jewitt (eds.), The Handbook of Visual Analysis (pp. 134-156). London: Sage. doi: 10.4135/9780857020062

Katz, S. (2005). Cultural Aging. Life Course, Lifestyle, and Senior Worlds. Peterborough: Broadview Press.

Katz, S. \& Calasanti, T. (2015). Critical perspectives on successful aging: Does it "appeal more than it illuminates". The Gerontologist 55(1): 26-33.

Kessler, E. M., Schwender, C. \& Bowen, C. E. (2010). The portrayal of older people's social participation on German prime-time TV advertisements. The Journals of Gerontology 65B(1): 97-106. 
Kivimäki, S. (2017). Ikää ihmettelemässä [Wondering about age]. Lähikuva 3: 62-77.

Kohlbacher, F. \& Chéron, E. (2012). Understanding silver consumers through cognitive age, health condition, financial status, and personal values: Empirical evidence from the world's most mature market Japan. Journal of Consumer Behavior 11: 179-188. doi: 10.1002/cb.382

Kress, G. \& van Leeuwen, T. (1996). Reading Images. The Grammar of Visual Design. London: Routledge. (2nd ed., 2004).

Lamb, E. \& Gentry, J. (2013). The denial of aging in American advertising: Empowering or disempowering? The International Journal of Aging and Society 2(4): 35-47.

Ledin, P. \& Machin, D. (2019). Forty years of IKEA kitchens and the rise of a neoliberal control of domestic space. Visual Communication 18(2): 165-187.

Lee, B., Kim, B.-C. \& Han, S. (2006). The portrayal of older people in television advertisements: A cross-cultural content analysis of the United States and South Korea. International Journal of Aging and Human Development 64: 279-297.

Loos, E. \& Ivan, L. (2018). Visual ageism. In L. Ayalon \& C. Tesch-Römer (eds.), Contemporary Perspectives on Ageism. International Perspectives on Ageing, (vol.19, pp. 163-176). Cham: Springer. doi:10.1007/978-3-319-73820-8_11

Lumme-Sandt, K. (2011). Images of aging in a 50+ magazine. Journal of Aging Studies 25: 45-51.

Meiners, N. H. \& Seeberger, B. (2010). Marketing to senior citizens: Challenges and opportunities. The Journal of Social, Political and Economic Studies 5(3): 293-328.

Miller, D. W., Leyell, T. S. \& Mazachek, J. (2004). Stereotypes of the elderly in US television commercials from the 1950s to the 1990s. International Journal of Aging and Human Development 58(4): 315-340.

Mosberg Iversen, S. \& Wilińska, M. (2020). Ageing, old age and media: Critical appraisal of knowledge practices in academic research. International Journal of Ageing and Later Life 14(1): 121-149. doi: 10.3384/ijal.1652-8670.2020.14.1

Moschis, G. P. \& Mathur, A. (2006). Older consumer responses to marketing stimuli: The power of subjective age. Journal of Advertising Research 46(3): 339-346. doi: 10.2501/S0021849906060326 
International Journal of Ageing and Later Life

National Readership Survey (NRS, 2003). London: National Readership Survey Ltd.

Nimrod, G. \& Ivan, L. (2019). The dual roles technology plays in leisure: Insights from a study of grandmothers. Leisure Sciences. doi: 10.1080/01490400.2019.1656123

Ong, F. S. \& Chang, H. K. (2009). Older people as models in advertisements: A crosscultural content analysis of two Asian countries. Journal of Business and Policy Research 4(2): 1-15.

Oró-Piqueras, M. \& Wohlmann, A. (eds.). (2016). Serializing Age: Aging and Old Age in TV Series. Aging Studies, Volume VII. Bielefeld: Transcript Verlag.

Pickard, S. (2016). Age Studies: A Sociological Examination of How We Age and Are Aged Through the Life Course. Los Angeles and London: Sage.

Prieler, M. (2012). Social groups in South Korean television advertising: Foreigners and older people. Keio Communication Review 34: 57-78.

Prieler, M., Ivanov, A. \& Hagiwara, S. (2016). The representation of older people in East Asian television advertisements. The International Journal of Aging and Human Development 85(1): 67-89. doi: $10.1177 / 0091415016677972$

Prieler, M., Kohlbacher, F., Hagiwara, S. \& Arima, A. (2009). How older people are represented in Japanese TV commercials: A content analysis. Keio Communication Review 31: 5-21.

Prieler, M., Kohlbacher, F., Hagiwara, S. \& Arima, A. (2011). Gender representation of older people in Japanese television advertisements. Sex Roles 64(5/6): 405-415.

Rose, G. (2012). Visual Methodologies. An Introduction to Researching with Visual Materials (3rd ed.). London: Sage.

Roy, A. \& Harwood, J. (1997). Underrepresented, positively portrayed: The representation of older adults in television commercials. Journal of Applied Communication Research 25(1): 39-56.

Rozanova, J. (2006). Newspaper portrayals of health and illness among Canadian seniors: Who ages healthily and at what cost? International Journal of Ageing and Later Life 1(2): 111-139.

Simcock, P. \& Sudbury, L. (2006). The invisible majority? Older models in UK television advertising. International Journal of Advertising 25: 7-106. 
Sudbury, L. \& Simcock, P. (2009). Understanding older consumers through cognitive age and the list of values: A U.K.-based perspective. Psychology and Marketing 26(1): 22-38. doi: 10.1002/mar.20260

Swayne, L. E. \& Greco, A. J. (1987). The portrayal of older Americans in television commercials. Journal of Advertising 16: 47-54.

Thimm, C. (1998). Die sprachliche Symbolisierung des Alters in der Werbung. In M. Jacker (ed.), Die Umworbene Gesellschaft. Analysen zur Entwicklung der Werbekommunikation [The language of old age symbolization in advertising] (pp. 114-140). Wiesbaden: Westdeutscher Verlag.

Timonen, V. (2016). Beyond Successful and Active Ageing. A Theory of Model Ageing. Bristol: Policy Press.

Twigg, J. \& Martin, W. (2015). The field of cultural gerontology. An introduction. In J. Twigg \& W. Martin (eds.), Routledge Handbook of Cultural Gerontology (pp. 1-15). London: Routledge.

Van Leeuwen, T. (2005). Introducing Social Semiotics. London: Routledge.

Williams, A., Ylänne, V. \& Wadleigh, P. M. (2010a). Images of older people in UK magazine advertising: Toward a typology. International Journal of Aging and Human Development 71(2): 83-114.

Williams, A., Ylänne, V., Wadleigh, P. M. \& Chen, C.-H. (2010b). Portrayals of older adults in UK magazine advertisements: Relevance of target audience. Communications: The European Journal of Communication Research 35(1): 1-27.

Willing's Press Guide to U.K. Media (2003). Chesham, Bucks: Romeike Ltd.

$\mathrm{Xu}, \mathrm{W}$. (2020). (Non-)Stereotypical representations of older people in Swedish authority-managed social media. Ageing \& Society 1-22. doi: 10.1017/S0144686X20001075

Ylänne, V. (2015). Representations of ageing in the media. In J. Twigg \& W. Martin (eds.), Routledge Handbook of Cultural Gerontology (pp. 369-376). London: Routledge.

Ylänne, V. (2020). Media positionings of older people. In A. Phelan \& D. O'Shea (eds.), Changing Horizons in the 21st century: Perspectives on Ageing (pp. 306-319). Newcastle upon Tyne: Cambridge Scholars Publishing.

Ylänne, V., Williams, A. \& Wadleigh, P. M. (2009). Ageing well? Older people's health and well-being as portrayed in UK magazine advertisements. International Journal of Ageing and Later Life 4(2): 33-62. 
International Journal of Ageing and Later Life

Yoon, H. \& Powell, H. (2012). Older consumers and celebrity advertising. Ageing \& Society 32: 1319-1336.

Zhang, Y. B, Song, Y. \& Carver, L. J. (2008). Cultural values and aging in Chinese television commercials. Journal of Asian Pacific Communication 18(2): 209-224. 